\title{
Proyeksi Astral: Analisis Wacana Fiksi Posmodern dalam Naskah Film Insidious
}

\author{
Ramis Rauf \\ Program Studi Sastra Inggris, Fakultas Ilmu Budaya, Universitas Halu Oleo \\ ramis.rauf@yahoo.com
}

\begin{abstract}
Abstrak
Penelitian ini bertujuan untuk menganalisis proyeksi astral sebagai sebuah konsep Death and Dying (kematian dan sekarat) dengan menggunakan pendekatan analisis wacana fiksi postmodern dalam naskah film Insidious. Penelitian ini menemukan bahwa proyeksi astral merupakan suatu kemampuan yang dimiliki oleh seseorang untuk meninggalkan tubuh fisiknya dan menjelajahi sebuah dunia astral atau dunia roh. Proyeksi astral adalah sebuah konsep kematian dan sekarat yang dihadirkan sebagai salah satu strategi fiksi postmodern yang dikenal sebagai strategi superimposition. Strategi ini mengilustrasikan ada dua dunia yang saling menumpuk dan bergandengan satu sama lain. Kehadirannya merupakan suatu cara untuk mendekonstruksi pemikiran mengenai sesuatu yang dianggap aneh (uncanny) dan tidak biasa sekaligus sebagai tandingan dari totalitas yang mengedepankan sisi ontologis mengenai keberadaan sesuatu. Dikatakan oleh McHale (1987) bahwa hal itu merupakan sister-genre dari fiksi posmodern. Fiksi ilmiah mengeksplorasi masalah ontologis dalam rangka membangun cerita yang baik sementara fiksi posmodern sekadar menyajikan permasalahan tersebut tanpa harus membangun cerita. Lebih lanjut, kedua genre dapat saling mengadopsi strategi-strateginya. Sementara itu, hubungan fiksi posmodern dan fiksi fantasi pun sama, saling meminjam strategi dalam mengeksplorasi permasalahan ontologis.
\end{abstract}

Kata kunci: insidious, proyeksi astral, kematian dan sekarat, analisis wacana, fiksi postmodern

\begin{abstract}
This study aims to analyze astral projection as a concept of Death and Dying by using a postmodern fiction discourse analysis perspective in Insidious movie script. This study found that astral projection is a capability possessed by a person to leave physical body and explore an astral world or the spirit world. Astral projection is a death and dying concept that is presented as one of the postmodern fictional strategies known as superimposition. This strategy illustrates that there are two worlds that accumulate and co-exist with each other. Its presence is a way of deconstructing thoughts about something that is considered uncanny and unusual as well as a counterpart of totality that puts the ontological side of the existence of something. It is said by McHale (1987) that it is a sister-genre of postmodern fiction. Science fiction explores ontological issues in order to build a good story while postmodern fiction simply presents the problem without having to build a story. Furthermore, both genres can adopt each other's strategies. Meanwhile, postmodern fictional relations and fantasy fiction are the same, borrowing strategies for exploring ontological issues.
\end{abstract}

Keywords: insidious, astral projection, death and dying, discourse analysis, postmodern fiction.

\section{Pendahuluan}

Dulunya, suatu karya sastra ditulis pengarang untuk menyampaikan pesan, namun di zaman sekarang karya sastra tidak hanya sekadar menyampaikan pesan, tetapi juga difungsikan untuk mengkonstruksi pesan melalui fitur-fiturnya. Kematian dan sekarat (Death and
Dying) merupakan salah satu simbol yang dihadirkan dalam sebuah karya sastra oleh pengarang yang difungsikan sebagai media untuk menyampaikan pesan sekaligus mengkontruksi pesan kepada pembaca (Be

Periode ini merupakan periode yang diidentikan sebagai era posmodernisme, mencitrakan 
suatu karya sastra yang menghadirkan dua dunia sekaligus, yakni dunia nyata dan dunia gaib. Dunia gaib oleh McHale (1987) disebutkan sebagai world next door merupakan dunia atau ruang yang tidak dapat disentuh, tidak terlihat dan tentunya tidak nyata. Todorov (dalam Hat Pujiati, 2009:2) mengkategorisasikan hal-hal yang berbau supernatural termasuk didalamnya keajaiban dan magis, sebagai fantasi. Akan tetapi, menurutnya fantasi merupakan genre yang berada pada posisi antara genre aneh (the uncanny dan genre mengagumkan (the marvelous).

Genre uncanny adalah sebuah genre yang memuat peristiwa-peristiwa supernatural, sebuah kondisi muslihat dan halusinasi, bahkan mati dan sekarat, yang dijelaskan melalui sudut pandang hukum alam. Berbeda halnya dengan genre the marvelous yang memuat kejadiankejadian supernatural yang dipaparkan dan diterima seolah hal tersebut merupakan sebuah norma (McHale, 1987:74).

Sejauh pembacaan peneliti, kedua genre di atas terinternalisasi ke dalam objek material yang hendak dianalisis. Karya yang selanjutnya digunakan sebagai ojbek dalam makalah ini ialah naskah film Insidious (2010), sebuah karya yang mengusung genre fantasi horor di dalamnya. Genre horor yang mengandung unsur astral, atau dalam bahasa lain disebut sebagai the further, dalam film ini merekognisi kenyataan bahwa semesta turut memberikan warna dalam penggambaran pluralitas semesta. Kemampuan proyeksi astral (astral projection) yang dimiliki oleh tokoh Josh dan anaknya, Dalton, dihadirkan dalam bentuk oposisi biner antara rasional dan irasionalitas, sekaligus sebagai konsep Death and Dying; dua konsep yang coba dihadirkan pengarang dalam rangka menyampaikan dan mengkontruksi sebuah pesan kepada pembaca mengenai peristiwa mati dan sekarat. Adapun masalah yang akan diungkap dalam makalah ini adalah "bagaimana pengarang mengungkapkan konsep death and dying dalam naskah film Insidious?".

\section{Proyeksi Astral : Wacana Fiksi Posmodern}

Proyeksi astral sebagai suatu konsep Death and Dying yang terdapat dalam naskah Insidious nyata tersurat dalam dialog antartokoh. Dua tokoh dalam skrip yang digambarkan memiliki kemampuan proyeksi astral adalah Josh dan Dalton. Perhatikan kutipan di bawah ini.

Elise: "Have you ever heard of astral projection?" Renai: "Out of body experiences?" (Elise nods) Elise: "I call them travellers. These are people with the ability to leave their physical body and travel to different places in an astral form. To some degree, we all have the ability to do it...but most of us subconsciously suppress it or don't how to access it." (Page 69, Scene 94, INT. Living Room, New House-Day) (Whannell, 2010).

Proyeksi astral merupakan suatu kemampuan yang dimiliki seseorang untuk meninggalkan tubuh fisiknya dan menjelajahi sebuah dunia astral atau dunia roh. Tokoh Elise dikisahkan berusaha menjelaskan kepada Reinaistri Josh-bahwa insiden yang dialami Dalton adalah salah satu bentuk proyeksi astral yang salah. Proyeksi yang menyebabkan tubuh astral Dalton tersesat di dunia roh. Dalam perspektif logika, Dalton digambarkan sebagai ia yang mengalami 
Poetika : Jurnal Ilmu Sastra

Vol. V No. 1, Juli 2017

koma, suatu kondisi ketika seseorang berada di antara hidup dan mati.

In the darkness, the towers metal skin is barely visible. Directly below the lamp is the very definition of innocence a sleeping child. His mouth is slack, eyelids twitching to dreams unseen. The truly deep sleep that an adult can only wish for) (Page 2, Scene 1, INT. Darkened Bedroom - Night) (Whannel, 2010).

Dalton disebutkan sebagai tokoh yang sedang tertidur. Ia tidur bukan dalam konsep yang konvensional, melainkan sekarat. Roh Dalton mengalami keterpisahan dengan fisiknya untuk beberapa waktu yang tidak dapat diperkirakan. Keadaan tidur demikian dapat dikatakan merujuk pada ihwal yang oleh Benstock (1969) disebut sebagai moribund. Moribund merupakan suatu kondisi yang menempatkan seseorang pada dua situasi yang bertentangan; hidup dan mati. Lebih jauh, melalui insidious, pengarang juga menampilkan the further atau "dunia samping" yang merupakan dunia roh tempat dimana tubuh astral Dalton tersesat. Kutipan berikut secara gamblang memberikan penekanan pada argumentasi di atas.

(Elise gazes up at the ceiling, as if looking into another world)

Elise: "In the further."

Renai: "What do you mean?"

Elise: "The further is that place beyond our perception, beyond our understanding of the physical world that we can see and touch. It is a place without clocks or measurements, without past or future...an infinite realm that holds all of our dreams... and all of our nightmares."

(She turns to look at them)
DOI $10.22146 /$ poetika.25994

ISSN 2338-5383 (print) ; 2503-4642 (online)

Elise: "That is where Dalton is." (Page 71, Scene 94, INT. Living Room, New HouseDay) (Whannell, 2010).

Penggalan kutipan di atas menunjukkan bahwa terdapat dunia samping yang oleh Tokoh Elise disebut sebagai the further. The further dapat dikatakan sebagai tempat di luar dari persepsi manusia mengenai dunia fisik yang dapat diindera, melalui penglihatan maupun sentuhan. Dunia samping dapat merujuk pada pemahaman tentang sebuah tempat tanpa dimensi waktu dan ruang, tanpa masa lalu atau masa depan; sebuah situasi yang mencengkram semua impian bahkan mimpi buruk. Michael Foucault (dalam McHale. 1987:44) menyebut "dunia samping" dengan istilah heterotopia, semacam ruang tempat sejumlah fragmen menunjukkan suatu kemungkinan akan adanya penumpukan dua dunia secara bersamaan.

Dunia samping, atau dalam prinsip etimologis dikenal sebagai world next door, merupakan struktur ontologis dari dunia yang diproyeksikan pada setiap kasus yang sama. Laku proyeksi ini lebih dikenal dengan istilah ontologi ganda (a dual ontology). Ontologi ganda merupakan struktur mencakup dua sisi dunia antara nyata dan gaib. Jarak yang berdiri di antara kedua sisi itu disebut sebagai heterotopia, sebuah gap yang mengandung ciri dari masing-masing sisi dunia yang terpisahkan. Untuk menghindari penggunaan istilah "dunia" sejumlah penulis postmodernis telah menemukan nama yang berbeda untuk jenis ruang heterotopian. Ruang yang kemudian disebut sebagai "zona".

Kehadiran dunia samping (heterotopia) ini mengindikasikan adanya keterkaitan antara dunia nyata dan dunia ghaib. Dunia nyata mewakili sega- 
la bentuk kehidupan, sementara dunia gaib menjadi representasi dari segenap sisi kematian (Whannell, 2010). Hal ini juga menunjukkan keberlanjutan epik melalui fantasi yang paling fenomenal, magis, dan dunia gaib. Kontinuitas epik merupakan salah satu jenis karakteristik postmodern. Epik diilustrasikan oleh heterotopia melalui keberadaan dunia samping. Disebut sebagai "dunia samping” karena dimarginalkan oleh kaum modern. Dunia samping dihadirkan dalam suatu karya posmodern untuk mendekonstruksi dunia nyata melalui nilai-nilai dan ideologi (Adi, 2012).

Di ruang inilah wujud astral tokoh Dalton. Ketersesatan Dalton dijelaskan sebagai bentuk deceased (Benstock, 1969), sebuah fase kematian yang terjadi ketika ruh berpisah dengan tubuh. Kenyataan ini membawa dampak yang demikian fatal bagi Dalton karena kematian yang sesungguhnya telah menanti di depan mata. Dickinsons (dalam Krueger, 2004) memang pernah menyebutkan bahwa kematian merupakan pintu menuju kehidupan abadi yang membahagiakan dalam pandangan umat kristiani, tetapi kita tidak sedang berada dalam perbincangan tentang seberapa beruntung kematian seseorang bagi dirinya.

The further dan proyeksi astral adalah dua hal yang aneh dan tidak masuk akal dalam kacamata masyarakat modern. Dua hal ini dihadirkan sebagai salah satu strategi fiksi postmodern yang dikenal sebagai superimposition. Strategi ini mengilustrasikan ada dua dunia yang saling menumpuk dan bergandengan satu sama lain. Kehadirannya merupakan suatu cara mendekon- struksi pemikiran mengenai sesuatu yang dianggap aneh dan tidak biasa. Hal ini juga mengindikasikan bahwa secara tidak sadar di sisi kehidupan nyata terdapat ruang dimensi lain yang selama ini kehadirannya menjadi marginal dan tidak diakui. Jika sesuatu yang aneh dan tidak biasa ini hadir maka akan terjadi interupsi realitas yang awalnya tidak problematis menjadi problematis. Realitas dalam zona individu sebagai dunianya akan menjadi tidak problematis (unproblematic) seiring hal tersebut menjadi realitas yang rutin. Selain itu, interupsi realitas juga dipandang sebagai pembuktian mengenai pemikiran posmodern yang menolak absoluditas sekaligus merayakan relativitas. Absoluditas menyebabkan keterpusatan pada sesuatu yang tunggal atau logosentrisme.

The further dan proyeksi astral dihadirkan sebagai fantasi juga tandingan dari totalitas yang mengedepankan sisi ontologis mengenai keberadaan sesuatu. Dikatakan oleh McHale bahwa hal itu merupakan sister-genre dari fiksi posmodern. Fiksi ilmiah mengeksplorasi masalah ontologis dalam rangka membangun cerita yang baik, sementara fiksi posmodern sekadar menyajikan permasalahan tersebut tanpa harus membangun cerita. Lebih jauh, kedua genre dapat saling mengadopsi strategi-strateginya. Sementara itu, hubungan fiksi posmodern dan fiksi fantasi pun sama, saling meminjam strategi dalam mengeksplorasi permasalahan ontologis. McHale (1987:62-83) menyatakan bahwa dalam perkembangannya, posmodern menemukan bentuknya yang baru, yakni posmodernist fantastic; penggunaan unsur-unsur fantastik pada fiksi 
posmodern yang supernatural dalam banal dan eksplorasinya terhadap masalah ontologis.

Kutipan di atas juga mengilustrasikan percakapan antara Elise dan Renai yang merupakan bentuk perlakuan karya posmodernis pada fantasi yang di dalamnya juga menggunakan strategi-strategi keraguan (hesitation), banalitas (banality), dan resistensi (resistance). Keraguan dalam strategi memperlakukan genre fantasi pada karya posmodernis adalah dengan menghadirkan dunia nyata dan dunia samping (McHale, 1987:74-5). Zona keraguan pun terbentuk dengan permainan susunan struktur ontologis dan atau epistemologis pada fantasi. Melalui permainan metafora hesitasi ini sering diulurulur dengan membuat keraguan kembali (hesitation-revisited) antara makna literal dan makna metaforis untuk melatardepankan dual ontologis. Banalitas (kewajaran) merupakan strategi perlakuan teks posmodernis terhadap fantasi dengan menempatkan sisi fantastis ke dalam logika ekstrim dalam dunia-dunia teks (McHale, 1987:76-7).

Josh: "This is a fantasy, and you need a therapist, not a member of the clergy." (Page 53, Scene 81, INT. Living room, New house-night) (Whannell, 2010).

Kutipan di atas secara eksplisit mendeskripsikan sikap resistensi Josh terhadap persoalan struktur ontologis dan epistemologis. Resistensi menjadi media tulisan posmodernis untuk menekankan kronfrontasi yang melekat pada fantasi (McHale, 1987:77-9). Dalam naskah film ini, terdapat tokoh Alanso (seorang mahasiswa) yang mencoba mendekonstruksi pemikiran Josh sebagai masyarakat modern berprofesi sebagai dosen:

Alanso: "Things are simple. You just can't see it. Put your faith in Him." (He takes a gold cross hanging on a necklace out of his shirt, kissing it and holding it up.) (Page 37, Scene 54, INT. Gymnasium, Forrester High School-Day) (Whannell, 2010).

Tokoh Alanso melakukan resistensi terhadap pernyatan Josh mengenai yang normal terhadap yang paranormal dengan perlakuan banal terhadap paranormal, sehingga perlakuan fiksi posmodernis terhadap fantasi tampak pasif dan membanalkan fantasi tersebut. Resistensi antara yang normal pada yang paranormal pun berlanjut tetapi diabaikan oleh karakter atau oleh pembaca. Dalam karya posmodernis, fantasi tetap berupa zona keraguan tetapi bukan lagi antara the marvelous dan the uncunny seperti diungkapkan Todorov, melainkan menurut McHale "between this world and the world next door" (McHale, 1987:75). Fantasi yang terjadi di Insidious mengeksploitasi unsur paranormal sebagai banalitas dari dunia tersebut. Keraguan antara dunia nyata dan dunia samping telah diliteralkan.

Penggalan kutipan di atas juga mendeskripsikan mengenai Alanso yang menjelaskan bahwa tidak semua hal bisa dijawab oleh ilmu pengetahuan. Ada kekuatan yang lebih tinggi bekerja. Dia percaya bahwa banyak hal tidak hanya diverifikasi melalui pengujian laboratorium dengan menggunakan penjelasan ilmiah yang logis karena tidak semua hal dapat dijelaskan dari sudut pandang keterlihatan objek termaksud. Menurutnya, kekuatan tertinggi adalah sesuatu 
Poetika : Jurnal Ilmu Sastra

Vol. V No. 1, Juli 2017
DOI 10.22146/poetika.25994

ISSN 2338-5383 (print) ; 2503-4642 (online) yang mengacu pada sang pencipta atau Tuhan.

Pencipta atau Tuhan mengacu kalimat put you faith in Him yang berarti "percayalah padaNYA". Hal ini dapat dibuktikan melalui simbol a gold cross yang berarti "salib emas" yang mengacu pada spiritualisme.

Era modernitas menyapu demikian banyak wujud spiritualisme, karena orang-orang dari kelompok modernitas percaya bahwa mereka hanya akan dapat menerima dan mengolah segala entitas yang logis dan terukur. Spiritualisme hanya terbatas pada kegiatan keagamaan, dan terindoktrinasi di balik dinding-dinding tempat ibadah. Fakta tersebut mengindikasikan bahwa para modernis secara tak sadar mengalami kematian spiritual atau living-dead karena berkurangnya nilai-nilai keagamaan di dalam diri mereka.

Pemahaman Josh mengenai sesuatu yang selama ini ia dan manusia modern langgengkan didekonstruksi pula melalui tokoh Dr. Sercarz, seorang dokter yang menangani Dalton yang sedang mengalami koma, disebabkan karena tubuh astralnya tersesat di zona roh (the further).

Dr. Sercarz: 'T wouldn't say we've exhausted every single angle... but we're close. The underlying cause is still known. The good news is that he's breathing without the use of a mechanical apparatus, and there are no lesions or hemorrhages in any of the $C T$ scans."

(Josh and Renai look in at their boy)

Josh: "So...there's no brain damage or...?"

Dr. Sercarz: 'None that we've detected. Technically, he's in coma. He doesn't respond to stimuli, he has no sleep-wake cycle, but there's no brain trauma or infection. His scans are normal. To be honest, I've never seen anything like it."

Josh: "That fall he took... I mean, it looked like be bit his head pretty bard."

Dr. Sercarz: "We definitely exhausted that possibility, but it was always doubtful. The cut was superficial, there wasn't even a skull fracture."

Josh: "So what do we do now? Does he stay bere?"

Dr. Sercarz: 'We'll conduct some further testing, but beyond that...I really don't know." (Page 24, Scene 34, INT. Hospital Room, ICU Unit-Day) (Whannell, 2010).

Penjelasan Dr, Sercarz mengenai hasil uji laboratorium yang dilakukan terhadap kondisi Dalton semakin menguatkan pernyataan mengenai kegagalan terbesar para modernis karena telah mengagungkan akal di atas segalanya. Kutipan di atas sekaligus meruntuhkan grand desain yang selama ini mereka-para modernis—langgengkan. Seolah-olah hidup dan kehidupan ini dapat berjalan atas kehendak akal manusia. Parahnya, mereka menyangkal eksistensi sang pencipta beserta entitas lain hanya karena tidak dapat terlihat (invinsible) secara kasat mata dan tidak dapat dibuktikan keberadaannya melalui uji laboratorium berserta penjelasan ilmiah yang terkait. Insidious mengaduk wacana di dalamnya dengan menggunakan heteroglosia pada wacana untuk menghadirkan dunia-dunia dalam wacana, hadir antara keteraturan dan ketidakteraturan, antara dunia orang dewasa dan anak-anak. Heteroglossia adalah istilah Bakhtin untuk ribuan strata diskursif dalam semua bahasa-bahasa 
nasional dan cara-cara strata ini menentukan operasi makna dalam tiap ungkapan (Makaryk, 1993:551).

\section{Penutup/Kesimpulan}

Berdasarkan penjelasan-penjelasan yang telah diungkapkan, dapat disimpulkan bahwa proyeksi astral adalah sebuah konsep kematian dan sekarat yang dihadirkan sebagai salah satu strategi fiksi postmodern yang dikenal sebagai strategi superimposition. Strategi ini mengilustrasikan ada dua dunia yang saling menumpuk dan bergandengan satu sama lain. Kehadirannya merupakan suatu cara untuk mendekonstruksi pemikiran mengenai sesuatu yang dianggap aneh (uncanny) dan tidak biasa sekaligus sebagai tandingan dari totalitas yang mengedepankan sisi ontologis mengenai keberadaan sesuatu. Dikatakan oleh McHale (1987) bahwa hal itu merupakan sister-genre dari fiksi posmodern. Fiksi ilmiah mengeksplorasi masalah ontologis dalam rangka membangun cerita yang baik sementara fiksi posmodern sekadar menyajikan permasalahan tersebut tanpa harus membangun cerita. Lebih lanjut, kedua genre dapat saling mengadopsi strategistrateginya. Sementara itu, hubungan fiksi posmodern dan fiksi fantasi pun sama, saling meminjam strategi dalam mengeksplorasi permasalahan ontologis

Konsep ini memberikan pemahaman kepada kita bahwa seseorang dapat memiliki kemampuan memproyeksikan tubuh astralnya untuk menjelajahi di luar dari alam semesta atau dunia samping (beterotopia) yang selama ini dianggap aneh (uncanny), bahkan tidak diacuhkan. Proyeksi astral ini bukan merupakan suatu kematian yang sesungguhnya, karena ketika terjadi proyeksi astral, tubuh astral atau roh seseorang akan keluar dan berpisah dari tubuh fisik, tetapi roh tersebut dapat kembali ke tubuh. Namun, fatalnya ketika roh tersebut tersesat di dunia astral (dunia roh), seseorang akan mengalami kematian yang sesungguhnya.

\section{Daftar Pustaka}

Adi, Ida Rochani. 2012. Popularizing Epic Narrative in George R. R. Martin's A Game of Thrones, Vol.24, Halaman 303-314. Yogyakarta: Pustaka Pelajar.

Bennett, Roger V. 1974. Death and the Curriculum. Chicago: American Education Research Association.

Benstock, Bernard. 1969. "The Dead" in James Joyce Dubliners: Critical Essay, Ed. Clive Hart. New York: Faber and Faber Copyright.

Krueger, Gretchen. 2004. "Death Be Not Proud:Children, Families and Cancer in Postwar America, Bulletin of the History of Medicine 78. Baltimore, Maryland: Johns Hopkins University Press.

Makaryk, Irena R. 1993. Encyclopedia of Contemporary Literary Theory. Canada: University of Toronto Press Incorporated.

McHale, Brian. 1987. Postmodenist Fiction (pp. 27, 45,46). Rouledge: Taylor and Francis Group. ISBN 0-203-39614-6.

Pujiati, Hat. 2009. Novel Enchanted dalam Kajian Posmodern Brian McHale. Tesis prasyarat kelulusan S-2 Program Studi Ilmu Sastra Universitas Gadjah Mada.

Whannell, Leigh. 2010. Insidious. American Supernatural Horror Movie. 